\section{Plasma leptin concentrations: no difference between diabetic Pima Indians with and without nephropathy}

Dear Sir,

For many small proteins, the kidney is the major route of clearance from the circulation, and recent evidence suggests that this is also true of leptin [1]. In order to test the effect of diabetic nephropathy on plasma leptin concentration, we compared plasma and urine leptin concentrations in twenty Pima Indians with well characterized renal function who participated in a longitudinal study of the natural history of diabetic nephropathy in Type II diabetes mellitus [2]. All subjects provided written informed consent. Ten subjects with nephropathy (urine albumin-to-creatinine (AC) ratio $\geq 300$ $\mathrm{mg} / \mathrm{g}$ ) were matched for age, sex, duration of diabetes and body mass index (BMI, $\mathrm{kg} / \mathrm{m}^{2}$ ) with ten diabetic controls subjects with normal urinary albumin excretion. Total leptin concentrations were measured in duplicate in plasma and urine obtained after an overnight fast using a solid phase sandwich enzyme immunoassay sensitive to $50 \mathrm{pg} / \mathrm{ml}$ [3]. Fasting plasma leptin concentrations were similar in both groups (Fig. 1) (15.5 [2.2-109.6] vs 14.1 [1.8-112.2] $\mathrm{ng} / \mathrm{ml}, p=0.83$, geometric mean [95\% confidence interval]). Plasma leptin concentration was related to BMI $(r=0.56, p=0.01)$, but not to glomerular filtration rate (GFR, assessed by the urinary clearance of iothalamate $)(r=-0.12, p=0.63)$ or the AC ratio $(r=0.07$, $p=0.77)$. Leptin was not detected in the urine of any of the subjects with normal urinary albumin excretion, but was found in seven of those with nephropathy $(3.8$ [1-14.8] ng/ $\mathrm{ml})$. In these subjects, the urinary leptin concentration was negatively correlated with GFR $(r=-0.91 p=0.01)$ and positively correlated to the AC ratio $(r=0.81, p=0.03)$. The three subjects with nephropathy but without measurable urinary leptin had a wide range of $\operatorname{GFR}(113,21$, and $113 \mathrm{ml} \cdot \min ^{-1} \cdot 1.73 \mathrm{~m}^{-2}$ ) but had AC ratios that were relatively low $(613,623$, and $2852 \mathrm{mg} / \mathrm{g})$. Thus, in the present study, nephropathy did not appear to affect total plasma leptin con-

Corresponding author: C. Wilson, M. D., Clinical Diabetes and Nutrition section, NIDDK/NIH, 4212 North 16th Street, Phoenix, AZ 85016, USA

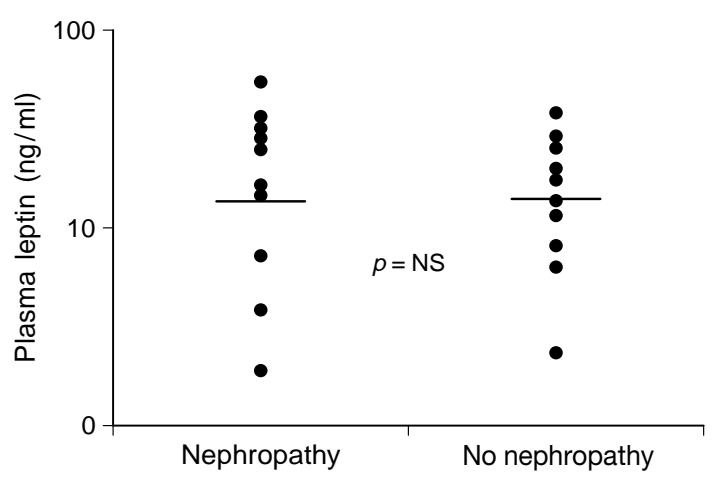

Abb.1. See text

centrations, whilst the appearance of leptin in the urine correlated with the degree of renal dysfunction.

Although the renal clearance of leptin is significant, alterations in renal function do not appear to alter plasma leptin concentration until severe. Plasma leptin concentrations are increased in haemodialysis patients, but are not related to residual glomerular filtration. [4] Shoji et. al. [5] found that $1 /$ creatinine contributed modestly to plasma leptin concentrations $(\beta=-0.282)$ when included in a multiple regression model with per cent body fat, waist to hip ratio, plasma insulin and gender. In a small study where aortic and renal vein leptin concentrations were measured, only $50 \%$ of the net renal extraction of leptin was related to the degree of renal function as measured by the serum creatinine [6].

The renal metabolism of insulin may provide a model for the renal metabolism of leptin. Insulin is filtered and removed from the proximal tubule by receptor-mediated endocytosis as well as by receptors on the tubular cells adjacent to the post glomerular renal circulation [7]. Once insulin enters the tubular cell, it is degraded and does not return to the systemic circulation. In healthy people, little if any insulin is present in the urine. In the presence of tubular dysfunction, the presence of insulin in the urine does not reflect excess loss of insulin from the plasma, but decreased renal degradation of insulin by the tubular cells. Consequently, plasma insulin levels are unchanged except in very advanced renal disease. Our results and those of other studies are consistent with a similar mechanism for the renal metabolism of leptin. 
In summary, diabetic nephropathy alters the renal metabolism of leptin, however, alterations in leptin metabolism that result in measurable plasma concentration differences are probably limited to patients with very severe renal disease. The physiologic consequences, if any, of these changes are not known.

Yours sincerely,

C. Wilson, R. Nelson, M. Nicolson, R. Pratley

\section{References}

1. Cumin F, Baum H-P, Levens N (1996) Leptin is cleared from the circulation primarily by the kidney. Int J Obesity 20: $1120-1126$

2. Nelson RG, Bennet PH, Beck GJ et al. for the Diabetic Renal Disease Study Group (1996) Development and progression of renal disease in Pima Indians with non-insulin- dependent diabetes mellitus. New Engl J Med 335: 1636-1642

3. Pratley R, Nicolson M, Bogardus C, Ravussin E (1996) Effects of acute hyperinsulinemia on plasma leptin concentrations in insulin-sensitive and insulin resistant Pima Indians. J Clin Endocrinol Metab 81: 4418-4421

4. Merabet E, Dagogo-Jack S, Coyne D W et al. (1997) Increased plasma leptin concentration in end-stage renal disease. J Clin Endocrinol Metab 82: 847-850

5. Shoji T, Nishizawa Y, Emoto M et al. (1997) Renal function and insulin resistance as determinants of plasma leptin levels in patients with NIDDM. Diabetologia 40: 676-679

6. Sharma K, Considine R, Michael B et al. (1997) Plasma leptin is partly cleared by the kidney and is elevated in haemodialysis patients. Kidney Int 51: 1980-1985

7. Rabkin R, Ryan MP, Duckworth WC (1984) The renal metabolism of insulin. Diabetologia 27: 351-357 